\title{
Historie van het onderwijs in de urologie
}

\author{
Ad Hendrikx ${ }^{1}$
}

Published online: 16 November 2016

(C) The Author(s) 2016. This article is available at SpringerLink with Open Access.

Samenvatting Opleiding kent geen einde. Vanuit de geschiedenis is, ook binnen de urologie, de vaardigheidstraining geëvolueerd van 'see one, do one, teach one' naar een gestructureerde skillslab training in modules. Verschillende organisaties zijn opgericht om dit doel te bereiken. Vijf promovendi hebben de onderwijskundige benadering van deze training wetenschappelijk onderbouwd.

Het Urologisch Vaardigheids Onderwijs in deze vorm is een verplicht onderdeel geworden van het curriculum voor aios. De eerste acht modules van dit curriculum zijn, mede dankzij de steun van velen in het hele land, geïmplementeerd. Terwijl deze modules qua inhoud en vorm verder worden verbeterd, zijn de volgende modules reeds in ontwikkeling, die ook nog in 2016 in gebruik zullen worden genomen. Alles is erop gericht om onderzoeksen behandelresultaten te verbeteren en de patiëntveiligheid te maximaliseren. Hierbij lijkt de invoer van toetsing een belangrijke rol te spelen.

Trefwoorden historie $\cdot$ training $\cdot$ testen

\section{History of training in urology}

Abstract Education is a never ending story. From the historical point of view is also in urology the skills training developed from: 'see one, do one, teach one' to a structured skills training in a skillslab. Several organizations were founded to reach this goal. Five PhD students dedicated their work to prove scientifically that the educational

dr. Ad Hendrikx

adhendrikx13@gmail.com

1 MEDEC, Nuenen, Nederland approach to training makes sense. The Urological Skills Training in this format is now a mandatory part of the training for residents. Thanks to the help of many organizations the first eight modules are now implemented all over the country. While those are still being improved, already new modules are created, that will be launched before the end of 2016.

Everything is focussed on both improvement in diagnostic and therapeutic results and optimizing patients safety. In this respect testing seems to be a key issue.

Keywords history $\cdot$ training $\cdot$ testing

\section{Introductie}

Reeds lang bestaat het inzicht dat je zowel tijdens, maar ook na de opleiding je vaardigheden moet blijven trainen en ontwikkelen. Life Long Learning!

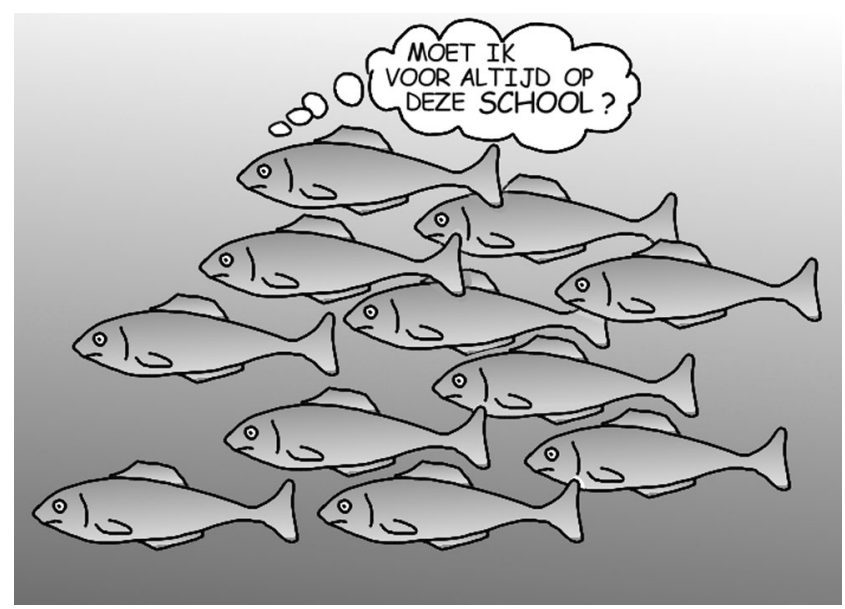




\section{Een historisch perspectief}

In 1984 was ik getuige van de introductie van de percutane nefrolitholapaxie (PNL) in het ziekenhuis in Roosendaal door Hugh Whitfield, een van de collega's van John Wickham, die deze techniek in het Institute of Urology, toen nog aan Shaftesbury avenue, had ontwikkeld [1]. Men mocht als uroloog deze ontwikkeling niet missen en dus nodigden ziekenhuizen een deskundige uit om naar Nederland te komen of kon men als individuele uroloog naar Londen afreizen om de PNL-vaardigheid in de tempel zelf te leren beheersen. Zo ontwikkelde iedere uroloog zich naar eigen inzicht en behoefte in het prachtige vak van de urologie. Al snel bleek dat deze leerschool van enkele uren, waarbij de vaardigheid vervolgens direct op de patiënt werd uitgevoerd, zeker voor de meerderheid van ons, onvoldoende was. Bij de PNL bleven stenen in de patiënt achter na de ingreep en er ontstonden complicaties. Learning by doing was niet 'altijd' het optimale leerproces, althans niet voor de patiënt.

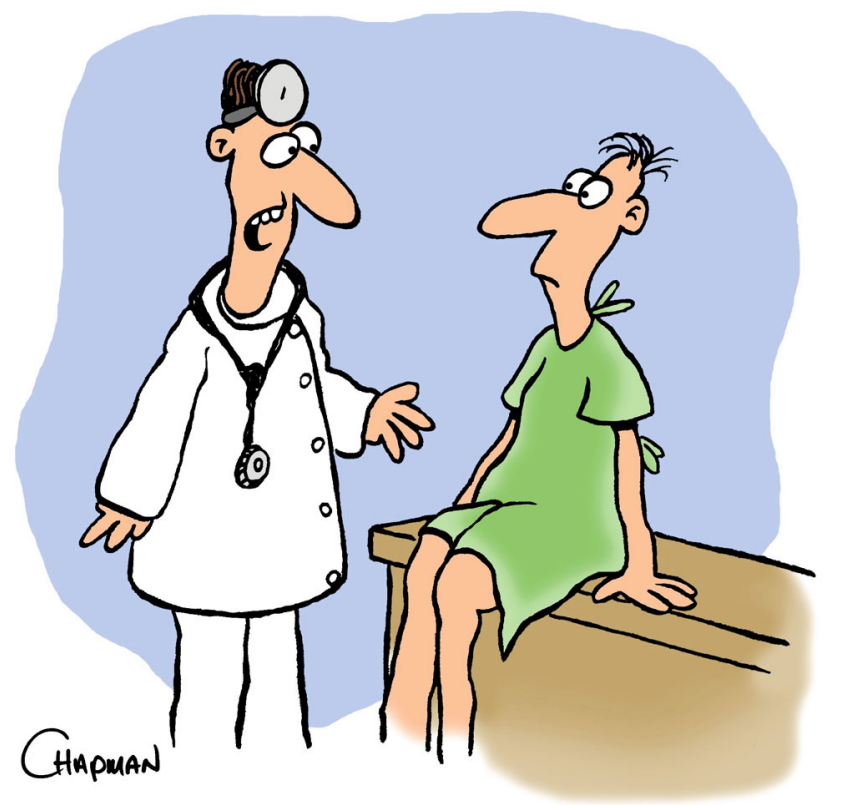

\section{"Of course your operation is absolutely necessary ... without it I can't finish medical school!"}

Mede daarom werden er onder de vlag van de SWEN vanaf 1987 jaarlijks cursussen en workshops georganiseerd voor urologen en aios om nieuwe technieken aan te leren en te verbeteren (echo nieren, echo prostaat, ureterorenoscopie (URS), de eerdergenoemde PNL, laparoscopie en brachytherapie). Dit gebeurde deels buiten de klinische setting in een soort 'skillslab', maar wel met medewerking van echte patiënten en door middel van life operaties, waarbij door experts werd gedemonstreerd hoe de ingreep moest worden uitgevoerd.

In de jaren erna groeide het bewustzijn dat eigenlijk alle onderzoeken en ingrepen die buiten de patiënt om getraind konden worden, ook echt in een skillslab zouden moeten worden geoefend, waarna in $\mathbf{2 0 0 5}$ de modernisering van de opleiding in gang is gezet, te beginnen bij de aios. Er is doelbewust naar gestreefd om onderwijskundige principes, zoals de herhaling, in deze nieuwe opleiding te introduceren. De bestaande praktische cursussen werden, met steun van het Concilium Urologicum, verplicht gesteld voor alle aios en het Urologisch Opleidings Instituut (UOI) werd opgericht om de logistiek van deze en ook andere cursussen op zich te nemen.

In 2006 werd het project officieel opgericht onder de naam 'Training in Urology', ofwel TIU. Albert Scherpbier werd de eerste hoogleraar onderwijskunde, die vanuit zijn vakgebied mede sturing gaf aan zowel de inhoud als de vorm. Diverse urologen werden uitgenodigd mee te werken aan het ontwerp van nieuwe trainingsmodules (simulatoren) voor echografie en endo-urologie, die zeker deels werden gevalideerd door promovendi, van wie Barbara Schout de eerste was en zij kon in 2010 haar promotietraject cum laude afronden [2].

In 2007 werd de SOM (Stichting Opleiding Medici) opgericht als overkoepelend orgaan, waar TIU onder functioneerde en waar alle financiële zaken voor promovendi en modules werden geregeld.

In 2008 werd binnen het Concilium de skillslabcommissie opgericht, om te inventariseren wat er in Nederland op lokaal niveau aan praktijktraining bestond, om daarin structuur aan te brengen, de leemtes op te vullen en zo een zo volledig mogelijk vaardigheidstrainingsprogramma te ontwerpen. In de commissie hadden urologen en aios als vertegenwoordigers van alle opleidingsclusters uit heel Nederland zitting. Door deze constructie werd een zo breed mogelijk draagvlak voor dit project gecreëerd.

Het was wellicht geen toeval dat in $\mathbf{2 0 0 9}$ het nieuwe Curriculum Urologie onder leiding van Jan Blom van de pers rolde met een goede definitie van eindtermen, waaraan een uroloog aan het einde van de opleiding moet voldoen. Ook staat in dit curriculum vermeld of, en zo ja op welk niveau, bepaalde delen van de urologie moeten kunnen worden uitgevoerd. Daarmee waren de kaders waarbinnen TIU de modules kon gaan uitbouwen, duidelijk gedefinieerd. In datzelfde jaar werd tijdens de nieuwe tweedaagse UPFRONT-cursus, waar aios aan het begin van hun urologische opleiding de eerste praktische basisvaardigheden aanleren, mede op aandringen van de Inspectie voor de Gezondheidszorg (IGZ), het eerste BLUS (Basic Laparoscopic Urological Skills) examen afgenomen met consequenties [3]. Als men op deze verplichte cursus het BLUS-examen (over kennis en laparoscopische basisvaardigheden) niet 
haalt, kan men niet deelnemen aan laparoscopische ingrepen [4]. Dit examen bleek niet voor iedereen even simpel.

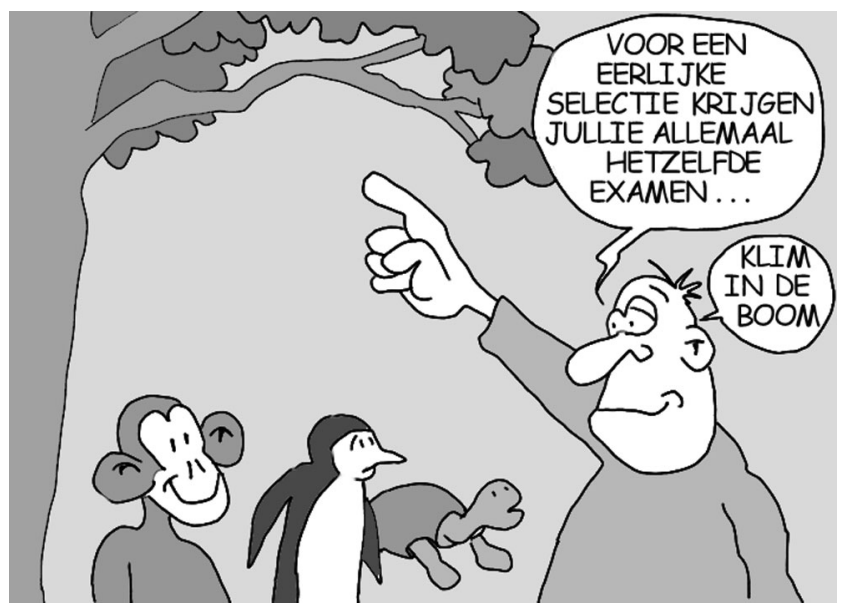

In 2012 wordt het team van opleiders en urologen (Bart Bemelmans, Fred Witjes, Rob Pelger, John Rietbergen, Evert Koldewijn, Ad Hendrikx), aios urologie, promovendi en medisch-onderwijskundigen (Jeroen van Merrienboer, Cees van der Vleuten), dat al betrokken was bij het project, versterkt met een expert op het gebied van patiëntveiligheid: prof. Cordula Wagner. Terwijl de ontwikkeling van trainingsmodules in volle gang was, promoveert de tweede promovenda binnen het project: Marjolein Persoon [5]. Het Concilium en de Commissie Cursorisch Onderwijs gaan officieel achter de invoering van het '40 uren Training in Urology project' staan en verklaren dit als verplichte NVUcursus. In september 2012 start de eerste fase van de implementatie van het 40-urenproject met de invoering van de eerste acht trainingsmodules in de eerste acht ziekenhuizen in Nederland.

Bij de evaluatie in 2013 zijn er, zoals verwacht, nog veel aspecten van het project naar voren gekomen die voor verbetering vatbaar zijn. Al deze aspecten zijn uitvoerig beschreven in het Rapport TIU 1e fase implementatie: 40 uren project en vormen de basis voor verdere ontwikkeling [6].

In 2014 stelt het Concilium implementatie van de eerste vijf modules in de opleiding verplicht voor heel $\mathrm{Ne}$ derland en het 40 urenproject wordt omgedoopt tot UVO: 'Urologisch VaardigheidsOnderwijs'. Jan Blom en ondergetekende begeleiden opleiders en aios in het hele land om deze implementatie te optimaliseren. Tevens promoveren de volgende twee promovendi Irene Tjiam [7] en Willem Brinkman [8].

In 2015 wordt door het UOI (Merije van der Sande) hard gewerkt aan de logistieke verbetering en worden er nieuwe modules ontworpen op advies van de Commissie Urologisch VaardigheidsOnderwijs (CUVO).
Deze nieuwe modules zullen in de loop van $\mathbf{2 0 1 6}$ worden geïntroduceerd, tevens het jaar dat de vijfde promovenda Heleen de Vries haar promotie zal afronden [9].

Naast het UVO bestaan er natuurlijk ook nog andere heel belangrijke trainingen om de aios tot een goed uroloog te vormen. Zo zijn er bijvoorbeeld de kadavercursussen in Leiden en Nijmegen, de female urology, de laparoscopiecursus, de stralingscursus en de theoretische cursussen.

De conclusie luidt dat de ontwikkelingen om de opleiding en dus de kwaliteit van zorg te verbeteren, nooit zullen ophouden. Steeds zal worden gezocht naar betere kosteneffectieve methoden om aios én professionals in dit proces te begeleiden. Het bereiken van een optimaal resultaat van een behandeling en het voorkomen van zelfs de kleinste complicaties dienen hierbij als insteek. Ook (gedeelten van) handelingen die een arts buiten de patiënt om kan leren, moeten zo geleerd en getraind worden dat onnodige schade aan de patiënt wordt voorkomen.

\section{Huidige ontwikkelingen}

Binnen het UVO richt de werkgroep zich nu op de ontwikkeling en validering van nieuwe simulatoren en modules. Daarbij wordt rekening gehouden met de onderwijskundige principes van bijvoorbeeld de herhaling, opleidingsaspecten die elders in dit tijdschrift uitvoeriger aan de orde komen. Ook is er aandacht voor een betere voorbereiding door alle partijen. Wellicht kan een teach the teacher-achtige cursus hierin een rol spelen.

De productspecialisten van de industrie zal opnieuw gevraagd worden hun belangrijke bijdrage aan het hele project te geven. Door het leveren van materiaal en hun ondersteuning bij de uitleg over de werking en risico's van hun apparatuur, hebben zij tot op heden een onmisbare rol gespeeld.

\section{Toetsen van kennis en kunde}

Om het rendement van een training te optimaliseren, lijkt toetsen van kennis en kunde een belangrijke toevoeging. Voor het aantonen van bevoegdheid en bekwaamheid wordt de vraag om zo'n toets (zoals bij het BLUS-examen) steeds dringender, ook voor de professional zelf.

Vanuit het Ministerie van Volksgezondheid, Welzijn en Sport (VWS), de IGZ en het NIVEL (Lisanne Verweij) wordt nu op het gebied van medische technologie concreet aan zo'n training met toets gewerkt. Als pilot is gekozen voor de onderwerpen robotchirugie en elektrochirurgie. Het plan is tevens deze training/toetssystematiek als kwaliteitsmeting breder op te zetten: niet alleen voor urologen, maar ook voor gynaecologen en chirurgen. Dit project zal moeten leiden tot een (zelf)evaluatie van het medisch-technisch 
handelen, met ingebouwde feedback. Het is een uitdaging om een simpel, kosteneffectief en valide meetinstrument te ontwikkelen, dat tegemoet zal komen aan deze eisen van de overheid, patiëntengroepen, maar ook aan de eisen van professionals zelf. In de toekomst zou videoanalyse daarin mogelijk nog een belangrijke rol kunnen gaan spelen [10]. De ultieme doelstelling blijft: de kwaliteit van het medisch specialistisch handelen steeds verder optimaliseren en de patiëntveiligheid verbeteren.

Leden van de TIU-projectgroep hebben daarom op verzoek van de redactie hun medewerking toegezegd om aan dit themanummer verder vorm en inhoud te geven. Alle belangrijke aspecten en onderdelen van training in de urologie komen in dit nummer aan bod. In het stuk van Schout leest $\mathrm{u}$ over curriculumontwikkeling, leerstijlen en generatieverschillen. Vervolgens wordt door Goldenberg en Van der Vleuten inhoudelijk dieper ingegaan op toetsing, een belangrijk, motiverend en onmisbaar onderdeel bij het ontwerpen van onderwijsprogramma's. Verweij belicht vervolgens de patiëntveiligheid binnen medisch onderwijs. Het themanummer eindigt met de visie van de 'oude' en de 'jonge' generatie, namens respectievelijk het Concilium Urologicum en de Jonge Urologen Commissie, op training in de urologie.

Ik wens u mede namens Barbara Schout, veel plezier bij het lezen van dit tijdschrift over verdieping in training en onderwijs: nuttig en leuk voor iedere uroloog!

Open Access This article is distributed under the terms of the Creative Commons Attribution 4.0 International License (http:// creativecommons.org/licenses/by/4.0/), which permits unrestricted use, distribution, and reproduction in any medium, provided you give appropriate credit to the original author(s) and the source, provide a link to the Creative Commons license, and indicate if changes were made.

\section{Literatuur}

1. Wickham JEA, Miller RA, Kellett MJ, Payne SR. Percutaneous nephrolithotomy: one stage or two? Br J Urol. 1984;56:582-5.

2. Schout BMA. Training in urology. From virtual to reality. (Proefschrift). Amsterdam: Vrije Universiteit; 2010.

3. Tjiam IM, Hendrikx AJM, Persoon MC, et al. The basic laparoscopic urological skills training: a newly developed and validated educational program. Urology. 2012;79(4):815-20.

4. Tjiam I, Hendrikx A. Eerste diploma's 'basis laparoscopische urologische skills' uitgereikt. Urograaf. 2010;5.

5. Persoon MC. Learning in urology. The influence of simulators and humans factors. (proefschrift). Maastricht: Universiteit Maastricht; 2012.

6. Schout BMA, Vries AH de, Koldewijn EL, et al. Rapport Training in Urology 1e Fase Implementatie 2012-2013: 40 uren project. Som; 2013.

7. Tjiam I. Learning in urology. Designing simulator based training and assessment. (proefschrift). Nijmegen: Radboud Universiteit; 2014.

8. Brinkman W. Learning laparoscopic and robotic surgery in urology. (proefschrift). Nijmegen: Radboud Universiteit; 2014.

9. Vries H de. Training in Urology: Time to test (proefschrift). Amsterdam: Vrije Universiteit; 2016.

10. Bonrath E, Gordon LE, Grantcharov TP. Characterising 'near miss' events in complex laparoscopic surgery through video analysis. BMJ Qual Saf. 2015;24:516-21.

dr. Ad Hendrikx uroloog 